\title{
Agregação de dados para análise da caminhabilidade: um estudo empírico
}

\author{
Data aggregation for walkability analysis: an empirical study
}

Ana Luiza Favarão Leão[a,b] (D), Letícia Cabrera[a,b] (D), Mariana Ragassi Urbano[a] (D) , Milena Kanashiro[a] (1)

[a] Universidade Estadual de Londrina (UEL), Londrina, PR, Brasil [b] Universidade Estadual de Maringá (UEM), Maringá, PR, Brasil

Como citar: Leão, A. L. F., Cabrera, L., Urbano, M. R., \& Kanashiro, M. (2020). Agregação de dados para análise da caminhabilidade: um estudo empírico. urbe. Revista Brasileira de Gestão Urbana, 12, e20190171. https://doi.org/10.1590/2175-3369.012.e20190171

\section{Resumo}

Uma das estratégias para avaliar a relação entre o ambiente construído e comportamentos ativos é a caminhabilidade, definida como a medida em que o ambiente construído apoia e incentiva a caminhada. Considerando tal cenário, a agregação de dados é fundamental, porém, ainda existem desafios metodológicos e uma latente falta de evidências experimentais sobre as unidades de agregação adequadas para a caminhabilidade no Brasil. Desta forma, o objetivo desta pesquisa é analisar unidades espaciais de agregação de dados para a mensuração objetiva da caminhabilidade e suas variáveis individuais no contexto de uma cidade brasileira. A partir da sistematização da caminhabilidade objetiva, através de um índice, em diferentes unidades de agregação de dados, e.g.: setor censitário e buffers de rede com raios de 200, 400 e 600m, uma análise de variabilidade e dispersão de dados foi conduzida. Inferiu-se dos resultados estatísticos que buffers de 400 e 600m, dimensões mais próximas de distâncias caminháveis médias, foram mais eficientes. Este estudo contribuiu metodologicamente para o avanço de abordagens contemporâneas para a compreensão da caminhabilidade por meio da análise quantitativa.

Palavras-chave: Caminhabilidade. Ambiente construído. Agregação de dados.

\section{Abstract}

One of the strategies for assessing the relationship between the built environment and active behaviors is walkability, defined as the extent to which the built environment supports and encourages walking. Given this scenario, data aggregation is critical, however, there are still methodological challenges and a latent lack of experimental evidence on appropriate aggregation units for walkability in Brazil. Thus, the objective of the present work is to analyze spatial data aggregation units for the objective measurement of walkability and its individual variables in the context of a Brazilian city. From the systematization a walkability index, in different data aggregation units, e.g.: census tract and network buffers with radii of

ALFL é arquiteta e urbanista, doutoranda em Arquitetura e Urbanismo, e-mail: analuiza.favarao@uel.br LC arquiteta e urbanista, mestranda em Arquitetura e Urbanismo, e-mail: leticiacabrera.uel@gmail.com MRU graduada em Estatística, doutora em Agronomia (Estatística e Experimentação Agronômica), docente, e-mail: mrurbanouel@gmail.com

MK é arquiteta e urbanista, doutora em Meio Ambiente e Desenvolvimento, docente, e-mail: milena@uel.br 
200, 400 and 600 meters, data variability, and dispersion analysis were conducted. It was inferred from statistical results that buffers of 400 and 600 meters, with dimensions closer to average walkable distances, were more efficient. This study methodologically contributed to the advancement of contemporary approaches to understanding walkability through quantitative analysis.

Keywords: Walkability. Built environment. Data aggregation.

\section{Introdução}

Estudos têm apontado o importante papel das cidades como suporte para o desenvolvimento de uma vida mais saudável (Ding \& Gebel, 2012; Frank et al., 2012; Humpel et al., 2002; Sallis et al., 1998). Tais abordagens emergem da discussão sobre o aumento, em níveis mundiais, da inatividade física (Brownson et al., 2009; Ng \& Popkin, 2012). A caminhada, independentemente do propósito, é a atividade física mais frequentemente relatada por adultos, sendo uma forma econômica, acessível e cotidiana de atividade física (Doescher et al., 2014).

Evidências crescentes indicam uma associação entre as características do ambiente construído e o deslocamento ativo (Brownson et al., 2009; Cervero et al., 2009; Ellis et al., 2016; Ewing \& Cervero, 2010; Moudon et al., 2019; Saelens \& Handy, 2008), quer seja para o deslocamento funcional/necessário, ou o opcional/recreacional (Carmona et al., 2010). Esta associação deu origem ao conceito de walkability (caminhabilidade), definido por Southworth (2005) como a extensão a que o ambiente construído dá o suporte e encoraja o caminhar. Ainda, em uma definição mais específica proposta por Leslie et al. (2007), como a medida em que características do ambiente construído e uso do solo podem, ou não, influenciar a caminhada para lazer, exercício ou recreação, para acessar serviços ou se deslocar para o trabalho.

Em termos de escala de análise, a caminhabilidade pode ser considerada em duas formas: micro e macroescalas (Park et al., 2015). A caminhabilidade na microescala é aquela diretamente percebida pelos pedestres, como a presença de árvores, largura e qualidade de calçadas. A macroescala, também chamada de meso, é relacionada a aspectos gerais da forma urbana que podem ser relevantes para comportamentos de caminhada, como a densidade residencial e o uso do solo. A macroescala pode ser eficientemente medida através de SIG (Sistemas de Informação Geográfica), já a microescala tem sua operacionalização mais onerosa e dependente de um maior número de pesquisadores (Kim et al., 2014).

Para a avaliação da caminhabilidade na mesoescala, os chamados Índices de Caminhabilidade têm sido uma das estratégias mais aplicadas mundialmente para a mensuração objetiva. Os índices são métricas compostas de variáveis, principalmente, da forma urbana que mantêm associações positivas com a caminhada para transporte (Christian et al., 2011). Tais métricas são compostas a partir de componentes principais do ambiente construído, mais comumente a densidade residencial, conectividade de ruas e uso misto do solo (Frank et al., 2006; Hino et al., 2012; Lotfi \& Koohsari, 2011; Owen et al., 2007; Reis et al., 2013; Sallis, 2009).

Para a sistematização dos índices como ferramentas de redução dos componentes físicos do ambiente construído, é necessária a predefinição de áreas para a agregação de dados. Por razões práticas, a delimitação espacial usual tem utilizado unidades administrativas como o census tracts e ZIP codes dos correios dos Estados Unidos da América, census wards na Grã-Bretanha (Sabel et al., 2013) e, no Brasil, os setores censitários do Instituto Brasileiro de Geografia e Estatística (IBGE). No entanto, apesar do uso dessas "unidades de conveniência", para inclusão e associação com fatores socioeconômicos, áreas de heterogeneidade espacial são observadas. Tal discussão aponta para o Modifiable Areal Unit Problem (MAUP), ou problema de área modificável (Flowerdew et al., 2008), em que a delimitação da área pode agregar características ambientais diferenciadas e, por consequência, inviabilizar internamente os estudos (Riva et al., 2008). A partir destas discussões, esta pesquisa realiza testes empíricos para analisar unidades espaciais de agregação de dados para a mensuração objetiva da caminhabilidade em quatro diferentes unidades de agregação de dados: setores censitários e buffers de rede sequenciais de $200 \mathrm{~m}$, $400 \mathrm{~m}$ e $600 \mathrm{~m}$. 
No Brasil, tal discussão se faz necessária, visto que evidências indicam que a quantidade de viagens ativas a pé é inversamente proporcional à dimensão da cidade - quanto menor a cidade, maiores as taxas de deslocamento ativo (ANTP, 2018). Neste sentido, pesquisas que buscam entender a influência do ambiente construído no deslocamento ativo são ainda mais relevantes em cidades onde o deslocamento não motorizado está mais presente. Estas cidades são entendidas como as cidades de até 100 mil habitantes (ANTP, 2018).

\section{Variáveis da caminhabilidade e unidades espaciais de agregação de dados}

A disseminação do uso dos índices de caminhabilidade (Frank et al., 2006, 2010; King et al., 2011; Owen et al., 2007; Reis et al., 2013; Sallis, 2009) deve-se à possibilidade de avaliar uma relação complexa entre ambiente-comportamento por meio de um indicador simples, robusto, reprodutível e verificável (Ellis et al., 2016). 0 índice de caminhabilidade mais difundido nas pesquisas científicas deste campo de estudos (Wang \& Yang, 2019) é o índice desenvolvido por Frank et al. (2010), o qual combina quatro variáveis: densidade residencial, taxa de ocupação comercial, densidade de intersecções e uso misto do solo.

A primeira, a densidade residencial, está vinculada à discussão de bairros compactos, com alta densidade residencial, que tendem a uma maior mistura de usos e facilitam o acesso a pé em atividades do cotidiano (Leslie et al., 2007).

A segunda, taxa de ocupação comercial, foi idealizada como um reflexo de um número maior de opções para destinos de bens e serviços (Leslie et al., 2007), mas principalmente como uma medida do design urbano voltado para os pedestres. Áreas da cidade com lotes comerciais de maiores extensões são menos propensas a terem um 'design amigável para os pedestres' (Cervero \& Kockelman, 1997).

A terceira variável, a densidade de intersecções, por outro lado, está relacionada ao aumento da conectividade de ruas, fato que pode proporcionar uma maior variedade de rotas e facilitar o acesso ao transporte público (Leslie et al., 2007).

Por fim, considerando que proximidade e conectividade são elementos sinérgicos que determinam distâncias entre atividades complementares (Owen et al., 2007), e contribuem para uma combinação de destinos residenciais e não residenciais (Mayne et al., 2013), a última variável refere-se ao uso misto do solo.

Tais variáveis agregadas em determinadas unidades espaciais podem ser sensíveis a dois efeitos do MAUP - de escala e de zoneamento. Os dados agregados em unidades espaciais diferenciadas - maiores ou menores - podem apresentar variações nos resultados, sendo este o efeito de escala (Openshaw, 1984). Por outro lado, o efeito de zoneamento pode ser observado quando, em uma dada escala, um conjunto de unidades espaciais é recombinado em diferentes zonas, possibilitando gerar variações nos dados e nos resultados das medições (Zhang \& Kukadia, 2005).

Logo, torna-se primordial estabelecer unidades que melhor representem as variações dos fatores que influenciam o comportamento relacionados à saúde e à caminhada (Diez Roux, 2001). Algumas técnicas e estratégias para análise de caminhabilidade vêm sendo testadas como alternativa ao uso de setores censitários. A delimitação de buffers com raios padronizados apresenta uma possibilidade para mitigar os efeitos do MAUP (Brownson et al., 2009). Inicialmente, estudos agregaram dados em buffers circulares (euclidianos), a partir da residência de um indivíduo. No entanto, é provável que este tipo de buffer não represente precisamente as relações entre o ambiente construído e a caminhada (Oliver et al., 2007). Na sequência, estudos indicaram uma maior eficiência no uso de buffers de rede (Frank et al., 2017). Esta metodologia de representação é baseada na criação de um polígono, construído a partir de uma distância fixa na rede viária em torno da residência de um indivíduo. Entende-se que buffers de rede representam melhor a área de espaços públicos acessível a um indivíduo (Cochran \& Wiley, 1977).

Ainda, para a definição de buffers não existe consenso em relação a um tamanho ideal e geralmente, de acordo com Hino et al. (2010), são utilizadas distâncias caminháveis que variam de $500 \mathrm{~m}$ a $1000 \mathrm{~m}$. Evidências da literatura sugerem que a maioria das distâncias caminhadas é menor do que $600 \mathrm{~m}$ e poucas ultrapassam os 
1200m (Houston, 2014). Gehl (2013) indica que, considerando a percepção das pessoas, a caminhada de 500m é um tamanho ideal, e Campoli (2012), a distância apropriada seria entre 450 e $800 \mathrm{~m}$.

Portanto, considerando os desafios metodológicos apresentados e a falta de evidências experimentais sobre as unidades de análise para a caminhabilidade nas cidades brasileiras, uma investigação da sensibilidade das medidas objetivas da caminhabilidade para outras representações de unidades espaciais se faz relevante.

Desta maneira, o objetivo desta pesquisa foi analisar unidades espaciais de agregação de dados para a mensuração objetiva da caminhabilidade e de suas variáveis individuais em uma cidade brasileira de pequeno porte. Os resultados contribuirão para subsidiar estratégias de medição de caminhabilidade nas cidades brasileiras de até 100 mil habitantes, inseridas em um contexto em desenvolvimento onde evidências são extremamente necessárias para atenuar os determinantes da inatividade física decorrentes da rápida urbanização, aumento do entretenimento passivo e do transporte motorizado (Bauman et al., 2012).

\section{Método}

\section{Descrição do objeto de estudo e unidades de análise}

Considerando o fenômeno sob análise como contemporâneo e contextual, portanto indissociável da sua própria definição, segundo Yin (2001), é adequado como estratégia de pesquisa o estudo de caso. A tática adotada foi a análise correlacional, a fim de identificar e entender padrões socioespaciais e quantificar a relação entre as variáveis (Groat \& Wang, 2013) a partir de procedimentos estatísticos.

A cidade de Rolândia (Figura 1) foi selecionada como estudo de caso por representar a média populacional das cidades brasileiras, com até 100 mil habitantes, e pela disponibilidade de dados. 0 município de Rolândia, no Estado do Paraná-Brasil, possui uma extensão de $454.174 \mathrm{~km}^{2}$ e uma população estimada em 2017 de 64.726 habitantes (IBGE, 2010b).

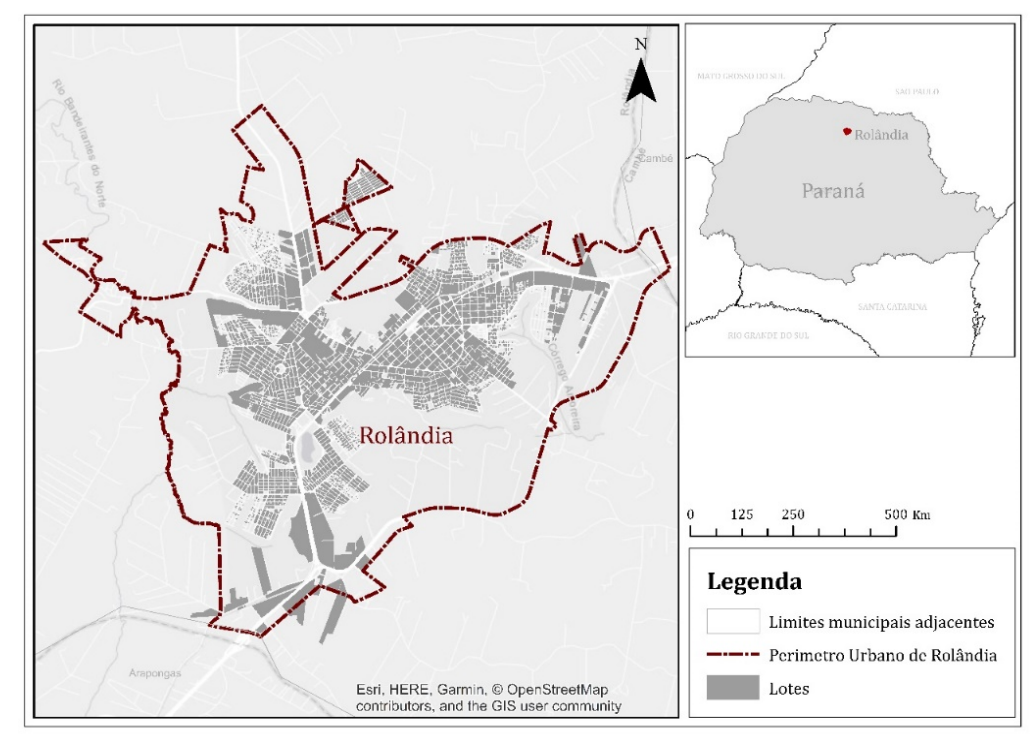

Figura 1 - Localização e malha urbana da cidade de Rolândia. Fonte: Autores (2018).

Atualmente, Rolândia está dividida em 74 setores censitários contidos no perímetro urbano. Foram excluídos 22 setores censitários para a análise: quatro caracterizados como rurais pelo IBGE; dois apresentavam somente o parcelamento do solo, e 16 setores pela inexistência de respondentes que caminhavam do questionário Origem-Destino (OD). Portanto, foram considerados 52 setores censitários (Figura 2). 


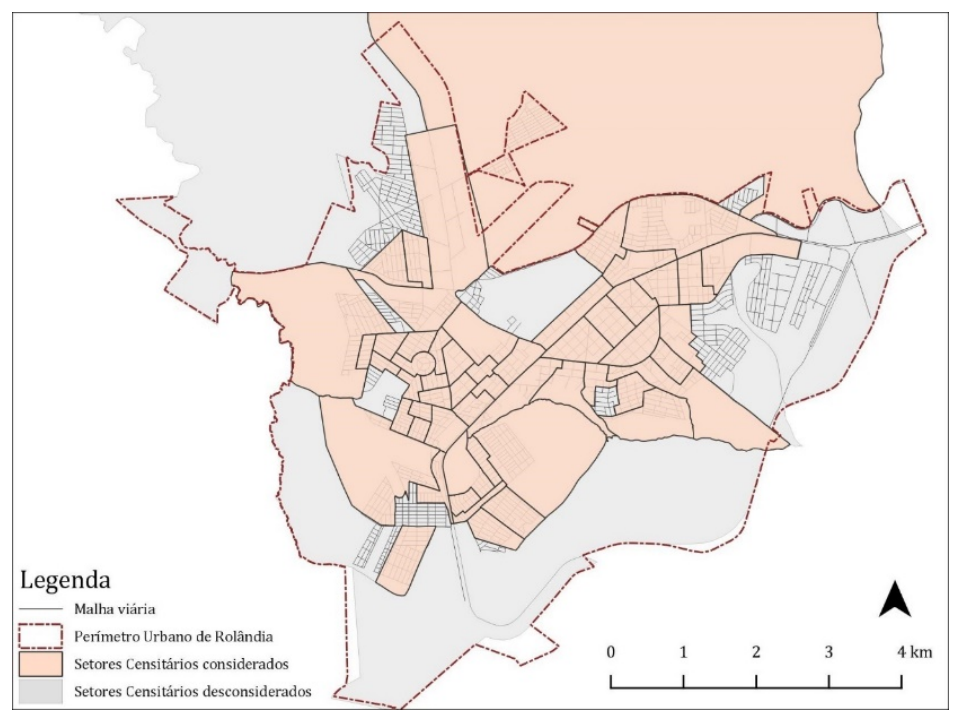

Figura 2 - Setores censitários do município de Rolândia. Fonte: IBGE (2010a), modificado pelos autores (2018).

Rolândia desenvolveu entre 2017 e 2018 seu Plano de Mobilidade, subsidiada pela pesquisa OrigemDestino (OD) domiciliar. Foram aplicados 756 questionários válidos, que representam 3,76\% dos 20.065 domicílios particulares permanentes (IPARDES, 2018). Para garantir uma estratificação uniforme, o número de domicílios foi distribuído por setor censitário (ITEDES, 2018).

O levantamento incluiu dados socioeconômicos e individuais de todos os membros das famílias, assim como o relato das viagens realizadas no dia anterior à aplicação do questionário. Em 142 residências foram reportadas viagens realizadas a pé, as quais foram geocodificadas com a finalidade de criar as unidades de agregação de dados da caminhabilidade.

As unidades de buffers de rede foram elaboradas em escalas de 200, 400 e 600m, estendendo-se ao longo da rede de ruas tendo como ponto central a residência dos 142 entrevistados que reportaram viagens a pé (Figura 3). Buffers foram gerados usando o software ESRI ArcGIS 10.6 no uso do Service Area Solver da extensão Network Analyst.

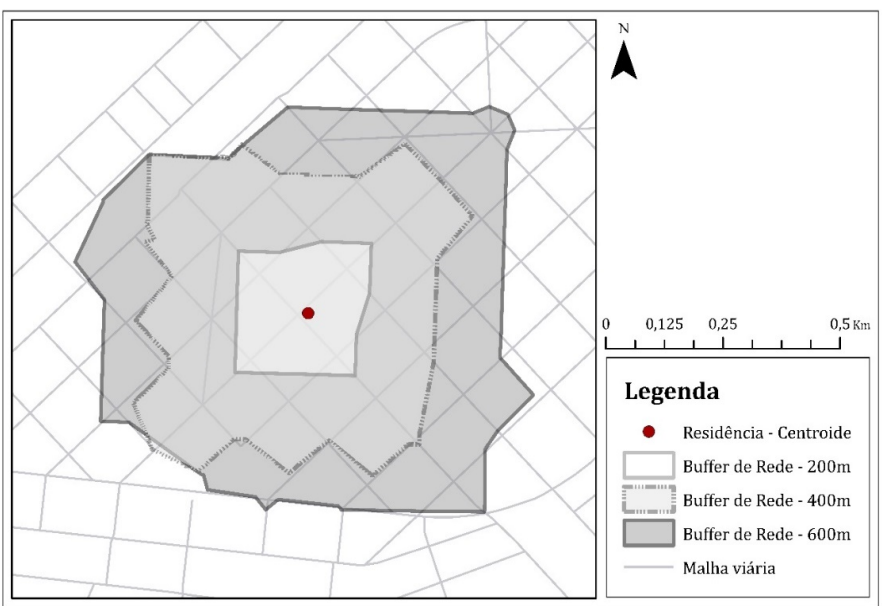

Figura 3 - Buffers de 200, 400 e 600 em torno de respondentes que reportaram caminhadas no município de Rolândia. Fonte: Autores (2018).

\section{Operacionalização da caminhabilidade}

Considerando as unidades de agregação de buffers de rede em diferentes raios métricos - 200m, 400m e $600 \mathrm{~m}$-, e setores censitários válidos para condução da análise, o índice de caminhabilidade foi calculado a partir da metodologia proposta por Frank et al. (2010). Quatro variáveis da forma urbana são 
consideradas em conjunto para descrever a caminhabilidade, sendo que o Escore-Z normaliza os dados. Esta estratégia objetiva de mensuração da caminhabilidade pode ser expressa pela seguinte Equação 1:

Índice de Caminhabilidade $=[(2 \times z-$ densidade de intersecções $)+(z-$ densidade residencial $)+$

$(z$-taxa de ocupação comercial $)+(z-$ uso misto do solo $)]$

A densidade de intersecções é uma medida relacionada à conectividade da rede viária, representada pela razão entre o número de cruzamentos verdadeiros (entre três ou mais vias) e o tamanho em $\mathrm{m}^{2} \mathrm{da}$ unidade de agregação considerada (Frank et al., 2010).

A densidade residencial é uma medida do número de unidades residenciais por unidade de área (Saelens et al., 2003). Após a contagem de todos os domicílios no município de Rolândia, a razão de densidade residencial foi calculada para cada unidade de agregação de dados considerada (setor censitário e buffers de rede de 200, 400 e $600 \mathrm{~m}$ ).

A taxa de ocupação comercial foi quantificada pela razão entre a área de lotes destinados ao uso comercial e a área da projeção da edificação destinada ao comércio, essa razão foi somada e agregada às unidades espaciais.

O uso misto do solo refere-se a uma medida da diversidade de usos presentes em uma unidade de área. No índice proposto por Frank et al. (2010), tal mensuração foi definida a partir da mistura entre cinco usos do solo: residencial, comercial, serviços, entretenimento (incluindo restaurantes, por exemplo) e institucionais (incluindo escolas, edifícios governamentais etc.), calculados via entropia. Assim, os valores variam de 0 a 1 , em que 0 indicaria a existência de apenas um uso em uma determinada área e 1 indicaria uma distribuição homogênea dos cinco usos. A entropia foi calculada através da Fórmula 2 baseada em (Shannon, 1948):

entropia $=-\sum k=\left(\frac{p k \times \ln p k}{\ln N}\right)$

onde $\mathrm{k}$ = categorias de uso do solo; $\mathrm{p}$ = proporção entre a área de uso do solo e a área do setor censitário; e $\ln =$ logaritmo natural (Frank et al., 2010).

Dados sobre uso do solo, quantidade de pavimentos e densidade residencial foram levantados por meio de ferramentas de imagem digital (datadas de 2017, 2015 e 2011) utilizando o Google Earth e Street View. Também foram realizadas visitas a campo pelos pesquisadores entre dezembro de 2017 e janeiro de 2018 para a conferência dos dados. Os dados de projeção de edificações e arruamento da cidade foram obtidos na prefeitura de Rolândia-PR. A partir da sistematização de cada variável do índice proposto por Frank et al. (2010), a caminhabilidade foi calculada em quatro unidades espaciais (setores censitários e buffers de 200, 400 e 600m) para uma análise comparativa. Para avaliar o efeito de zoneamento foram utilizadas áreas com delimitação diferentes (setores e buffers), e para avaliar o efeito de escala foram utilizados diferentes tamanhos de buffers $(200 \mathrm{~m}, 400 \mathrm{~m}$ e $600 \mathrm{~m})$. A construção dos índices foi realizada em um sistema de informações geográficas com o uso do software ArcGIS for Desktop 10.6.

Para testar as unidades espaciais utilizadas para o cálculo da caminhabilidade, foi realizada a análise da variabilidade dos dados em cada uma das unidades de agregação por meio do software R (R Core Team, 2018). Para avaliar a variação e a homogeneidade dos dados agregados às unidades espaciais, foi utilizado o coeficiente de variação (CV), uma medida de dispersão de dados em relação à média, obtida pela razão entre o desvio-padrão de uma variável dividido por sua média. Um coeficiente de variação alto indica que a dispersão dos dados em relação à média é muito grande, ou seja, a dispersão relativa é alta e o inverso também é verdadeiro. É importante notar que o CV é adimensional, isto é, não tem unidade de medida (Vieira, 2008). Em função desta característica, é útil para comparar a dispersão relativa de variáveis medidas em diferentes unidades, como é o caso dos dados espaciais apresentados neste estudo.

Para os CVs das variáveis da forma urbana e para o índice de caminhabilidade, o teste assintótico foi realizado para a verificação de igualdade ou não entre os CVs de k variáveis (Feltz \& Miller, 1996), 
disponibilizado no pacote do R cvequality (Versão 0.1.3; Marwick \& Krishnamoorthy, 2018; Marwick \& Krishnamoorthy, 2018). Resultados do teste assintótico de igualdade entre os CVs são representados por letras e interpretados em comparações nas linhas. Letras iguais indicam a inexistência de diferenças entre os CVs, e letras diferentes indicam que há diferenças entre os CVs. Posterior ao teste, foram calculados os intervalos de confiança de $95 \%$ com correção de Bonferroni para os CVs usando o pacote do R MBESS (Kelley, 2018).

\section{Resultados e discussões}

0 índice de caminhabilidade proposto por Frank et al. (2010), bem como as variáveis individuais da forma urbana, foram calculados e mapeados nas quatro unidades de agregação de dados: unidades de buffer de 200m, 400m e 600m, e os setores censitários definidos pelo IBGE (2010a) (Figura 4).

Os dados obtidos foram analisados inicialmente com o uso de técnicas descritivas. Na Tabela 1 são apresentados os valores descritivos de mínimos, máximos, médias, medianas e desvios-padrão. Tal análise possibilita a detecção da distribuição dos dados, seu comportamento e valores atípicos.

A aplicação do índice de caminhabilidade, em diferentes escalas e unidades, demonstrou a variabilidade de acordo com a delimitação da área de agregação dos dados evidenciando os efeitos do MAUP.

Tabela 1 - Estatísticas descritivas da forma urbana caminhável em diferentes unidades

\begin{tabular}{|c|c|c|c|c|c|}
\hline & & \multicolumn{3}{|c|}{ Unidades de Buffer } & \multirow{2}{*}{$\frac{\text { Unidade do Censo }}{\text { Setor censitário }}$} \\
\hline & & $200 \mathrm{~m}$ & $400 \mathrm{~m}$ & $600 \mathrm{~m}$ & \\
\hline Tamanho médio $\left(\mathrm{m}^{2}\right)$ & & 71470,28 & 277128,25 & 600242,88 & 1093841,07 \\
\hline \multirow{7}{*}{$\begin{array}{l}\text { Densidade de } \\
\text { Intersecções }\end{array}$} & Mín. & 0,0000338 & 0,0000382 & 0,0000461 & 0,0000016 \\
\hline & Máx. & 0,0003225 & 0,0001927 & 0,0001621 & 0,0002369 \\
\hline & Média & 0,0001143 & 0,0001027 & 0,0000981 & 0,0000844 \\
\hline & Mediana & 0,0001104 & 0,0000991 & 0,0000968 & 0,0000796 \\
\hline & Desvio-Padrão & 0,0000477 & 0,0000290 & 0,0000225 & 0,0000503 \\
\hline & Mín. & 0,0006521 & 0,0009607 & 0,0008879 & 0,0000019 \\
\hline & Máx. & 0,0072243 & 0,0036676 & 0,0025562 & 0,0030178 \\
\hline \multirow[t]{4}{*}{ Densidade residencial } & Média & 0,0022671 & 0,0018464 & 0,0016763 & 0,0011956 \\
\hline & Mediana & 0,0020245 & 0,0017241 & 0,0016176 & 0,0011203 \\
\hline & Desvio-Padrão & 0,0010337 & 0,0005164 & 0,0003713 & 0,0008300 \\
\hline & Mín. & 0,0000000 & 0,0000000 & 0,1571126 & 0,0000000 \\
\hline \multirow{5}{*}{$\begin{array}{c}\text { Taxa de ocupação } \\
\text { comercial }\end{array}$} & Máx. & 0,9999771 & 0,8686104 & 0,8638241 & 0,9086378 \\
\hline & Média & 0,5121575 & 0,5762327 & 0,5498512 & 0,5437953 \\
\hline & Mediana & 0,6166545 & 0,6198295 & 0,5929040 & 0,6429405 \\
\hline & Desvio-Padrão & 0,2916086 & 0,1972837 & 0,1792388 & 0,2609069 \\
\hline & Mín. & $-0,2203537$ & $-0,2095873$ & $-0,1896026$ & 0,0000572 \\
\hline \multirow{5}{*}{$\begin{array}{l}\text { Uso Misto do Solo } \\
\text { (entropia) }\end{array}$} & Máx. & 0,4223657 & 0,2674092 & 0,2370462 & 0,7080140 \\
\hline & Média & $-0,0701252$ & $-0,0705838$ & $-0,0683986$ & 0,2638892 \\
\hline & Mediana & $-0,1009314$ & $-0,0901936$ & $-0,0929047$ & 0,2562761 \\
\hline & Desvio-Padrão & 0,1227995 & 0,1063284 & 0,0917310 & 0,1383941 \\
\hline & Mín. & $-0,2174013$ & $-0,1840206$ & 0,0410654 & 0,0037118 \\
\hline \multirow{4}{*}{$\begin{array}{c}\text { Índice de } \\
\text { Caminhabilidade }\end{array}$} & Máx. & 1,1499185 & 0,9245611 & 0,8992382 & 1,3805013 \\
\hline & Média & 0,4445279 & 0,5094322 & 0,4833251 & 0,8090488 \\
\hline & Mediana & 0,5521867 & 0,5563135 & 0,5203831 & 0,9072210 \\
\hline & Desvio-Padrão & 0,3251177 & 0,1960690 & 0,1586550 & 0,3286330 \\
\hline
\end{tabular}

Fonte: Autores (2018).

Notadamente, a variância dos indicadores da forma urbana consideradas aqui, representada pelo desvio-padrão, diminui, de uma forma geral, com o aumento da escala de buffers, um processo de homogeneização dos dados como indicado pela literatura (Zhang \& Kukadia, 2005), deixando claro o efeito de escala gerado pelo MAUP. 
Áreas dadas como altamente caminháveis agregadas pelos setores censitários (Figura 4a), quando agregadas por outra unidade espacial, como os buffers, apresentaram resultados diversos denotando o efeito de zoneamento.
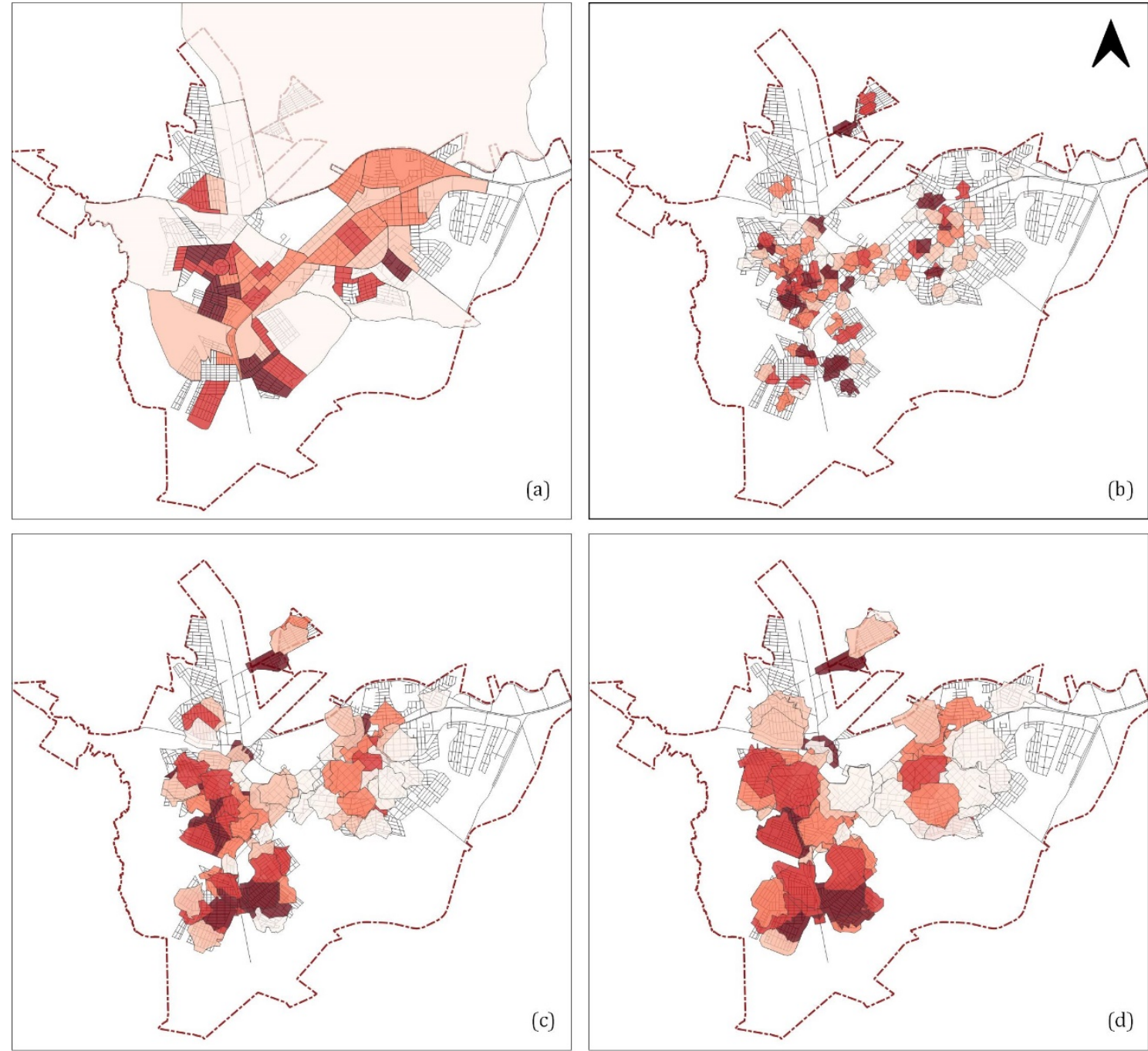

\section{Legenda}

Índice de Caminhabilidade BAIXA

Perímetro Urbano de Rolândia Malha viária

ALTA

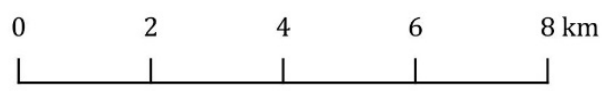

Figura 4 - Índices de Caminhabilidade calculados nos (a) setores censitários, por buffer de (b) 200m, (c) 400m e (d) 600m. Fonte: Grupo de pesquisa Design Ambiental Urbano (2017). Elaborado pelos autores (2018).

Na Tabela 2 são apresentados os CVs para as variáveis da forma urbana e para o índice de caminhabilidade. Considerando os CVs relacionados ao Tamanho médio $\left(\mathrm{m}^{2}\right)$ das unidades analisadas, a sensibilidade dos resultados em relação à escala de agregação fica evidente. Buffers de $600 \mathrm{~m}$ apresentam maior variação em relação a outros tamanhos de buffer, e setores censitários variam de forma extrema em relação a todas as outras unidades analisadas. Verifica-se ainda que a amplitude do intervalo de confiança indica uma maior margem de erro nos setores censitários.

Verificou-se na densidade de intersecções, em relação aos valores de CV, que o buffer de rede de $200 \mathrm{~m}$ não apresentou diferença em relação ao setor censitário e ao buffer de $400 \mathrm{~m}$. 0 buffer de $400 \mathrm{~m}$ 
apresentou diferença apenas em relação ao setor censitário. 0 buffer de $600 \mathrm{~m}$ apresentou diferença entre o buffer de $200 \mathrm{~m}$ e o setor censitário. Interpreta-se que unidades de menores extensões geográficas não sejam ideais, por capturarem pouco da forma da cidade. Assim como unidades com grandes variações de área, como setores censitários, que acabam por abranger diferentes tamanhos de quarteirões e quantidade de intersecções diferentes. Infere-se assim que buffers de 400 e $600 \mathrm{~m}$ têm possibilidade de serem mais uniformes.

Tabela 2 - Coeficiente de variação (CV) e Intervalos de Confiança (IC) dos dados das variáveis da forma urbana e do índice de caminhabilidade

\begin{tabular}{|c|c|c|c|c|}
\hline & \multicolumn{3}{|c|}{ Unidades de Buffer } & \multirow{2}{*}{$\begin{array}{l}\text { Unidade do Censo } \\
\text { Setor censitário } \\
\end{array}$} \\
\hline & $200 \mathrm{~m}$ & $400 \mathrm{~m}$ & $600 \mathrm{~m}$ & \\
\hline & $\mathrm{CV}^{*}(\mathrm{IC})$ & CV (IC) & CV (IC) & CV (IC) \\
\hline Tamanho médio (m²) & $\begin{array}{c}17.06 \\
(14.71 ; 20.38) \mathbf{a}\end{array}$ & $\begin{array}{c}16.54 \\
(14.30 ; 19,75) \mathbf{a}\end{array}$ & $\begin{array}{c}20.19 \\
(17.39 ; 24.17) \mathbf{a}\end{array}$ & $\begin{array}{c}402.65 \\
(176.0 ; 650.78) b\end{array}$ \\
\hline Densidade de Intersecções & $\begin{array}{c}41.74 \\
(32.30 ; 50.95) \text { ac }\end{array}$ & $\begin{array}{c}28.20 \\
(24.17 ; 33.85) \mathbf{a b}\end{array}$ & $\begin{array}{c}22.98 \\
(19.76 ; 27.57) \mathbf{b}\end{array}$ & $\begin{array}{c}59.58 \\
(46.11 ; 84.03) c\end{array}$ \\
\hline Densidade residencial & $\begin{array}{c}45.60 \\
(38.42 ; 55.97) \mathbf{a}\end{array}$ & $\begin{array}{c}27.97 \\
(23.97 ; 33.57) \mathbf{b}\end{array}$ & $\begin{array}{c}22.15 \\
(19.06 ; 26.56) \mathrm{b}\end{array}$ & $\begin{array}{c}69.43 \\
(52.89 ; 100.96) \mathbf{a}\end{array}$ \\
\hline $\begin{array}{c}\text { Taxa de ocupação } \\
\text { comercial }\end{array}$ & $\begin{array}{c}56.94 \\
(47.40 ; 71.20) a\end{array}$ & $\begin{array}{c}34.24 \\
(29.21 ; 41.38) \mathbf{b}\end{array}$ & $\begin{array}{c}32.598 \\
(27.85 ; 39.33) \mathbf{b}\end{array}$ & $\begin{array}{c}47.98 \\
(37.75 ; 65.56) a b\end{array}$ \\
\hline Uso Misto do Solo (entropia) & $\begin{array}{c}175.12 \\
(123.68 ; 301.09) \mathbf{a}\end{array}$ & $\begin{array}{c}150.64 \\
(110.24 ; 238.63) a\end{array}$ & $\begin{array}{c}134.11(100.54 \\
201.96) \mathbf{~ a ~}\end{array}$ & $52.44(41.01 ; 72.50) \mathbf{b}$ \\
\hline Índice de Caminhabilidade & $\begin{array}{c}73.14 \\
(59.71 ; 94.37) \mathbf{a}\end{array}$ & $\begin{array}{c}38.49 \\
(32.64 ; 46.77) \mathbf{b}\end{array}$ & $\begin{array}{c}32.83 \\
(38.05 ; 39.61) \mathbf{b}\end{array}$ & $40.62(32.26 ; 54.56) \mathbf{b}$ \\
\hline
\end{tabular}

*A nível de $5 \%$ de probabilidade, coeficientes de variação seguidos da mesma letra na linha não diferem significativamente entre si. Fonte: Autores (2018).

De certa forma, os CVs relacionados à densidade residencial indicaram fenômeno similar, onde foram definidos dois grupos: primeiro, uma variabilidade alta, representada pelo buffer de $200 \mathrm{~m}$ e o setor censitário; e o segundo, uma regularidade nos resultados, representada pelos buffers de $400 \mathrm{~m}$ e $600 \mathrm{~m}$. Interpreta-se então que, para a variável densidade residencial, unidades muito pequenas ou com muita variabilidade em extensão geográfica não são ideais.

Por outro lado, em relação à taxa de ocupação comercial, embora as unidades de buffer de $200 \mathrm{~m}$ e o setor censitário tenham apresentado CVs maiores, o resultado indica que não há diferenças estatisticamente significativas entre as diferentes unidades espaciais.

Quanto ao uso misto do solo, calculado por entropia, uma diferença estatisticamente significativa foi constatada nos resultados do setor censitário, indicando que sua a grande variabilidade de dimensões territoriais não impactou negativamente a representação deste tipo de dado. 0 uso da entropia considera o equilíbrio dos usos e pode ser categorizada como uma medida de homogeneidade. Portanto, unidades maiores, como setores censitários, podem ser mais adequadas para mensuração do uso misto do solo em relação ao equilíbrio, como já indicado em estudos anteriores (Shashank \& Schuurman, 2019).

E, por fim, os resultados em relação ao índice de caminhabilidade indicaram que as unidades mais eficientes foram os buffers de 400 e $600 \mathrm{~m}$ e os setores censitários, não existindo diferenças significativas entre eles. Menos eficiente foi o buffer de rede com raio de $200 \mathrm{~m}$. A performance inferior desta escala pode ser explicada por evidências da literatura, que unidades espaciais de menor extensão têm a tendência de apresentar homogeneidade interna, porém pouca heterogeneidade entre si (Flowerdew et al., 2008).

Diferenças significativas não foram identificadas na análise dos CVs relacionados ao índice de caminhabilidade e setores censitários, buffers de 400 e de $600 \mathrm{~m}$. Entretanto, interpreta-se que o intervalo de confiança para o setor censitário, que representa a margem de erro da estimativa, possuiu a maior amplitude. Conjectura-se que, por conta da variabilidade em relação à maneira como foram delimitados os setores, o efeito de zoneamento do MAUP ficou evidente, tornando a área pouco adequada para a análise do ambiente construído no deslocamento a pé. 
Considerando uma mesma estratégia de análise espacial, buffers, verifica-se que o buffer de $400 \mathrm{~m}$ apresenta maior amplitude de IC do que o de $600 \mathrm{~m}$. Desta forma, entende-se que a maior escala de buffer se mostrou mais estável em relação à homogeneidade de resultados do índice de caminhabilidade.

Com o objetivo de analisar unidades de agregação para a mensuração objetiva da caminhabilidade no contexto de uma cidade brasileira de pequeno porte, este estudo constatou que tanto a unidade de agregação dos setores censitários quanto a unidade de buffer de rede em sua menor escala apresentaram resultados menos satisfatórios. Desta forma, discute-se que unidades governamentais agregadas apresentam desvantagens expressivas para a representação da caminhabilidade, devido a grandes variações de escala e zoneamento. E infere-se que unidades muito pequenas, como os buffers de rede de $200 \mathrm{~m}$, dificilmente conseguem abranger dados suficientes para representar a caminhabilidade mensurada por meio do índice de caminhabilidade como proposto por Frank et al. (2010).

\section{Conclusão}

Evidências sólidas para orientar diretrizes eficientes de planejamento urbano, que considerem o deslocamento ativo, partem da necessidade de sistematização efetiva de dados do ambiente construído. Desta forma, esta pesquisa buscou contribuir com a discussão de agregação de dados para a análise da caminhabilidade. Sabe-se que limites arbitrários podem resultar em resultados e diretrizes equivocadas, assim, o estudo buscou, por meio da análise de unidades espaciais de agregação de dados para a mensuração objetiva da caminhabilidade, levantar evidências que contribuam para subsidiar estratégias que possam mitigar comportamentos sedentários.

Na interpretação de relações estatísticas baseadas em bancos de dados agregados, conclui-se que é necessário considerar os efeitos do MAUP em função do profundo impacto que o design das unidades de área pode exercer sobre os padrões e relacionamentos observados. Eles nos obrigam a reconhecer que as unidades de área não são neutras nem estáveis (Cockings \& Martin, 2005). Entretanto, quando os pesquisadores têm acesso a dados de nível individual, as técnicas de exploração da sensibilidade dos resultados permitem a exploração sistemática da influência da agregação nas relações e nos padrões observados.

Os resultados do presente estudo sugerem que a utilização de buffers de tamanhos adequados pode contribuir metodologicamente para o avanço das pesquisas sobre o ambiente construído, a atividade física e o caminhar. Infere-se dos resultados estatísticos que buffers de 400 e $600 \mathrm{~m}$, dimensões mais próximas de distâncias caminháveis médias, foram mais eficientes na mensuração da caminhabilidade neste estudo de caso. A inadequação das unidades governamentais de setores censitários fica evidente em função da grande variabilidade de dados em várias das características da forma urbana caminhável aqui consideradas.

Este estudo contribui de forma importante, avançando a abordagem atual para a compreensão da caminhabilidade por meio da análise quantitativa. 0 padrão emergente de estudos sobre influências do ambiente no comportamento é complexo e desafiador para síntese (Owen et al., 2007), e evidências indicam que algumas descobertas foram relatadas de forma inconsistente (Gebel et al., 2007). Desta forma, como sugerido por outros autores (Mitra \& Buliung, 2012; Zhang \& Kukadia, 2005), a seleção de unidades espaciais que leva em conta a interação entre o comportamento humano e o ambiente físico circundante pode ser uma abordagem útil a ser considerada.

Limitações do trabalho seriam a não inclusão de aspectos subjetivos, como a percepção, senso de comunidade, identidade local ou o sentido de pertencimento (Barczak \& Duarte, 2012). Ainda, estudos como o conduzido por Mitra \& Buliung (2012) não encontraram coeficientes estatisticamente significativos em qualquer tamanho de buffer. Perchoux et al. (2016) concluíram que o ambiente percebido pelos residentes é marcadamente diferente daquilo representado por buffers de rede, tanto em termos de tamanho quanto de exposição relacionada à caminhabilidade. Portanto, a análise conduzida 
com buffers, apesar de apresentar mais homogeneidade, pode ainda não representar totalmente a área de deslocamento do indivíduo.

Estudos futuros são necessários para avaliar quais variáveis e procedimentos devem ser considerados para delimitação de unidades de análise mais homogêneas e adequadas à realidade brasileira.

\section{Referências}

Associação Nacional de Transportes Públicos - ANTP. (2018). Sistema de Informações da Mobilidade Urbana: relatório geral 2016. ANTP, 1(1), 1-110. Recuperado em 29 de novembro de 2019, de http://files.antp.org.br/simob/simob-2016-v6.pdf

Barczak, R., \& Duarte, F. (2012). Impactos ambientais da mobilidade urbana: cinco categorias de medidas mitigadoras. urbe. Revista Brasileira de Gestão Urbana, 4(1), 13-32. http://dx.doi.org/10.1590/S217533692012000100002.

Bauman, A. E., Reis, R. S., Sallis, J. F., Wells, J. C., Loos, R. J. F., \& Martin, B. W. (2012). Correlates of physical activity: why are some people physically active and others not? Lancet, 380(9838), 258-271.

http://dx.doi.org/10.1016/S0140-6736(12)60735-1. PMid:22818938.

Brownson, R. C., Hoehner, C. M., Day, K., Forsyth, A., \& Sallis, J. F. (2009). Measuring the built environment for physical activity: state of the science. American Journal of Preventive Medicine, 36(4, Supl), S99-S123.e12. http://dx.doi.org/10.1016/j.amepre.2009.01.005.

Campoli, J. (2012). Made for walking: density and neighborhood form (2nd ed.). Cambridge: Lincoln Institute of Land Policy.

Carmona, M., Heath, T., Tiesdell, S., \& Oc, T. (2010). Public places, urban spaces: the dimensions of urban design. Oxford: Architectural Press.

Cervero, R., \& Kockelman, K. (1997). Travel demand and the 3Ds: density, diversity, and design. Transportation Research Part D, Transport and Environment, 2(3), 199-219. http://dx.doi.org/10.1016/S1361-9209(97)00009-6.

Cervero, R., Sarmiento, O. L., Jacoby, E., Gomez, L. F., \& Neiman, A. (2009). Influences of built environments on walking and cycling: lessons from Bogotá. International Journal of Sustainable Transportation, 3(4), 203-226. http://dx.doi.org/10.1080/15568310802178314.

Cockings, S., \& Martin, D. (2005). Zone design for environment and health studies using pre-aggregated data. Social Science \& Medicine, 60(12), 2729-2742. http://dx.doi.org/10.1016/j.socscimed.2004.11.005. PMid:15820583.

Cochran, W. G., \& Wiley, J. (1977). Sampling techniques (3rd ed.). New York: John Wiley \& Sons.

Christian, H., Giles-Corti, B., Knuiman, M., Timperio, A., \& Foster, S. (2011). The influence of the built environment, social environment and health behaviors on body mass index: results from RESIDE. Preventive Medicine, 53(1-2), 57-60. http://dx.doi.org/10.1016/j.ypmed.2011.05.004. PMid:21609730.

Diez Roux, A. V. (2001). Investigating neighborhood and area effects on health. American Journal of Public Health, 91(11), 1783-1789. http://dx.doi.org/10.2105/AJPH.91.11.1783. PMid:11684601.

Ding, D., \& Gebel, K. (2012). Built environment, physical activity, and obesity: what have we learned from reviewing the literature? Health \& Place, 18(1), 100-105. http://dx.doi.org/10.1016/j.healthplace.2011.08.021. PMid:21983062.

Doescher, M. P., Lee, C., Berke, E. M., Adachi-mejia, A. M., Lee, C., Stewart, O., Patterson, D. G., Hurvitz, P. M., Carlos, H. A., Duncan, G. E., \& Moudon, A. V. (2014). The built environment and utilitarian walking in small U. S. towns. Preventive Medicine, 69, 80-86. http://dx.doi.org/10.1016/j.ypmed.2014.08.027. PMid:25199732.

Ellis, G., Hunter, R., Tully, M. A., Donnelly, M., Kelleher, L., \& Kee, F. (2016). Connectivity and physical activity: using footpath networks to measure the walkability of built environments. Environment and Planning. B, Planning \& Design, 43(1), 130-151. http://dx.doi.org/10.1177/0265813515610672. 
Ewing, R., \& Cervero, R. (2010). Travel and the built environment. Journal of the American Planning Association, 76(3), 265-294. http://dx.doi.org/10.1080/01944361003766766.

Feltz, C. J., \& Miller, G. E. (1996). An asymptotic test for the equality of coefficients of variation from $k$ populations. Statistics in Medicine, 15(6), 647-658. http://dx.doi.org/10.1002/(SICI)1097-0258(19960330)15:6<647::AIDSIM184>3.0.C0;2-P. PMid:8731006.

Flowerdew, R., Manley, D. J., \& Sabel, C. E. (2008). Neighbourhood effects on health: does it matter where you draw the boundaries? Social Science \& Medicine, 66(6), 1241-1255. http://dx.doi.org/10.1016/j.socscimed.2007.11.042. PMid:18177988.

Frank, L. D., Fox, E. H., Ulmer, J. M., Chapman, J. E., Kershaw, S. E., Sallis, J. F., Conway, T. L., Cerin, E., Cain, K. L., Adams, M. A., Smith, G. R., Hinckson, E., Mavoa, S., Christiansen, L. B., Hino, A. A., Lopes, A. A., \& Schipperijn, J. (2017). International comparison of observation-specific spatial buffers: maximizing the ability to estimate physical activity. International Journal of Health Geographics, 16(1), 1-13. http://dx.doi.org/10.1186/s12942-0170077-9. PMid:28114945.

Frank, L. D., Sallis, J. F., Conway, T. L., Chapman, J. E., Saelens, B. E., \& Bachman, W. (2006). Many pathways from land use to health: associations between neighborhood walkability and active transportation, body mass index, and air quality. Journal of the American Planning Association, 72(1), 75-87. http://dx.doi.org/10.1080/01944360608976725.

Frank, L. D., Sallis, J. F., Saelens, B. E., Leary, L., Cain, L., Conway, T. L., \& Hess, P. M. (2010). The development of a walkability index: application to the neighborhood quality of life study. British Journal of Sports Medicine, 44(13), 924-933. http://dx.doi.org/10.1136/bjsm.2009.058701. PMid:19406732.

Frank, L., Kavage, S., \& Devlin, A. (2012). Health and the built environment: a review (21 p.). Washington: Urban Design 4 Health. Recuperado em 29 de novembro de 2019, de http://www.wma.net/en/20activities/30publichealth/30healthenvironment/Built_Env-Final_ReportAugust2012.pdf

Gebel, K., Bauman, A. E., \& Petticrew, M. (2007). The Physical environment and physical activity: a critical appraisal of review articles. American Journal of Preventive Medicine, 32(5), 361-369.

http://dx.doi.org/10.1016/j.amepre.2007.01.020. PMid:17478260.

Gehl, J. (2013). Cidade para pessoas (2. ed.). São Paulo: Perspectiva.

Groat, L., \& Wang, D. (2013). Architectural research methods. New Jersey: John Wiley \& Sons.

Hino, A. A. F., Rech, C. R., Gonçalves, P. B., Hallal, P. C., \& Reis, R. S. (2012). Projeto Espaços de Curitiba, Brasil: aplicabilidade de métodos mistos de pesquisa e informações georreferenciadas em estudos sobre atividade física e ambiente construído. Revista Panamericana de Salud Publica, 32(3), 226-233. http://dx.doi.org/10.1590/S102049892012000900008. PMid:23183563.

Hino, A. A. F., Reis, R. S., \& Florindo, A. A. (2010). Ambiente construído e atividade física: uma breve revisão dos métodos de avaliação. Revista Brasileira de Cineantropometria \& Desempenho Humano, 12(5), 387-394.

http://dx.doi.org/10.5007/1980-0037.2010v12n5p387.

Houston, D. (2014). Implications of the modifiable areal unit problem for assessing built environment correlates of moderate and vigorous physical activity. Applied Geography, 50, 40-47.

http://dx.doi.org/10.1016/j.apgeog.2014.02.008.

Humpel, N., Owen, N., \& Leslie, E. (2002). Environmental factors associated with adults' participation in physical activity: a review. American Journal of Preventive Medicine, 22(3), 188-199. http://dx.doi.org/10.1016/S07493797(01)00426-3. PMid:11897464.

Instituto Brasileiro de Geografia e Estatística - IBGE. (2010a). Bases e referenciais: malhas digitais: censo de 2010. Recuperado em 15 de Janeiro de 2018, de https://mapas.ibge.gov.br/bases-e-referenciais/basescartograficas/malhas-digitais 
Instituto Brasileiro de Geografia e Estatística - IBGE. (2010b). Panorama da cidade de Rolândia. Recuperado em 15 de Janeiro de 2018, de https://cidades.ibge.gov.br/brasil/pr/rolandia/panorama

Instituto Paranaense de Desenvolvimento Econômico e Social - IPARDES. (2018). Caderno estatístico município: município de Rolândia. Rolândia.

Instituto Tecnologia Desenvolvimento Econômico Social - ITEDES. (2018). PlanMob: plano municipal de mobilidade urbana de Rolândia-PR. Rolândia.

Kelley, M. K. (2018). MBESS: the MBESS R Package R Package Version 4.4.3. Vienna: R Foundation for Statistical Computing. Recuperado em 21 de Novembro de 2018, de https://cran.r-project.org/package=MBESS

Kim, S., Park, S., \& Lee, J. S. (2014). Meso- or micro-scale? Environmental factors influencing pedestrian satisfaction. Transportation Research Part D, Transport and Environment, 30, 10-20.

http://dx.doi.org/10.1016/j.trd.2014.05.005.

King, A. C., Sallis, J. F., Frank, L. D., Saelens, B. E., Cain, K., Conway, T. L., Chapman, J. E., Ahn, D. K., \& Kerr, J. (2011). Aging in neighborhoods differing in walkability and income: associations with physical activity and obesity in older adults. Associations with Physical Activity and Obesity in Older Adults, 73(10), 1525-1533.

http://dx.doi.org/10.1016/j.socscimed.2011.08.032. PMid:21975025.

Leslie, E., Cerin, E., duToit, L., Owen, N., \& Bauman, A. (2007). Objectively assessing 'walkability' of local communities: using gis to identify the relevant environmental attributes. In P. C. Lai, \& A. S. H. Mak (Eds.), Gis for health and the environment: development in the Asia-Pacific region (pp. 90-104). Berlin: Springer.

http://dx.doi.org/10.1007/978-3-540-71318-0_7.

Lotfi, S., \& Koohsari, M. J. (2011). Neighborhood walkability in a city within a developing country. Journal of Urban Planning and Development, 137(4), 402-408. http://dx.doi.org/10.1061/(ASCE)UP.1943-5444.0000085.

Marwick, B., \& Krishnamoorthy, K. (2018). cvequality: tests for the equality of coefficients of variation from multiple groups. Vienna: R Foundation for Statistical Computing.

Mayne, D. J., Morgan, G. G., Willmore, A., Rose, N., Jalaludin, B., Bambrick, H., \& Bauman, A. (2013). An objective index of walkability for research and planning in the Sydney Metropolitan Region of New South Wales, Australia: an ecological study. International Journal of Health Geographics, 12, 61. http://dx.doi.org/10.1186/1476-072X-1261. PMid:24365133.

Mitra, R., \& Buliung, R. N. (2012). Built environment correlates of active school transportation: neighborhood and the modifiable areal unit problem. Journal of Transport Geography, 20(1), 51-61.

http://dx.doi.org/10.1016/j.jtrangeo.2011.07.009.

Moudon, A. V., Huang, R., Stewart, O. T., Cohen-Cline, H., Noonan, C., Hurvitz, P. M., \& Duncan, G. E. (2019). Probabilistic walking models using built environment and sociodemographic predictors. Population Health Metrics, 17(1), 7. http://dx.doi.org/10.1186/s12963-019-0186-8. PMid:31159824.

Ng, S. W., \& Popkin, B. M. (2012). Time use and physical activity: a shift away from movement across the globe. Obesity Reviews, 13(8), 659-680. http://dx.doi.org/10.1111/j.1467-789X.2011.00982.x. PMid:22694051.

Oliver, L. N., Schuurman, N., \& Hall, A. W. (2007). Comparing circular and network buffers to examine the influence of land use on walking for leisure and errands. International Journal of Health Geographics, 6(1), 41.

http://dx.doi.org/10.1186/1476-072X-6-41. PMid:17883870.

Openshaw, S. (1984). The modifiable areal unit problem. Journal of the American Statistical Association, 29(185), 169. http://dx.doi.org/10.2307/2277827.

Owen, N., Cerin, E., Leslie, E., duToit, L., Coffee, N., Frank, L. D., Bauman, A. E., Hugo, G., Saelens, B. E., \& Sallis, J. F. (2007). Neighborhood walkability and the walking behavior of Australian adults. American Journal of Preventive Medicine, 33(5), 387-395. http://dx.doi.org/10.1016/j.amepre.2007.07.025. PMid:17950404.

Park, S., Choi, K., \& Lee, J. S. (2015). To walk or not to walk: testing the effect of path walkability on transit users' access mode choices to the station. International Journal of Sustainable Transportation, 9(8), 529-541.

http://dx.doi.org/10.1080/15568318.2013.825036. 
Perchoux, C., Chaix, B., Brondeel, R., \& Kestens, Y. (2016). Residential buffer, perceived neighborhood, and individual activity space: New refinements in the definition of exposure areas - The RECORD Cohort Study. Health \& Place, 40, 116-122. http://dx.doi.org/10.1016/j.healthplace.2016.05.004. PMid:27261634.

R Core Team (2018). R: a language and environment for statistical computing. Vienna: R Foundation for Statistical Computing. Recuperado em 29 de novembro de 2019, de http://www.r-project.org/

Reis, R. S., Hino, A. A. F., Rech, C. R., Kerr, J., \& Hallal, P. C. (2013). Walkability and physical activity. American Journal of Preventive Medicine, 45(3), 269-275. http://dx.doi.org/10.1016/j.amepre.2013.04.020. PMid:23953352.

Riva, M., Apparicio, P., Gauvin, L., \& Brodeur, J. M. (2008). Establishing the soundness of administrative spatial units for operationalising the active living potential of residential environments: an exemplar for designing optimal zones. International Journal of Health Geographics, 7(1), 1-13. http://dx.doi.org/10.1186/1476-072X-7-43. PMid:18671855.

Sabel, C. E., Kihal, W., Bard, D., \& Weber, C. (2013). Creation of synthetic homogeneous neighbourhoods using zone design algorithms to explore relationships between asthma and deprivation in Strasbourg, France. Social Science \& Medicine, 91, 110-121. http://dx.doi.org/10.1016/j.socscimed.2012.11.018. PMid:23332654.

Saelens, B. E., \& Handy, S. L. (2008). Built environment correlates of walking. Medicine and Science in Sports and Exercise, 40(7, Supl), S550-S566. http://dx.doi.org/10.1249/MSS.0b013e31817c67a4. PMid:18562973.

Saelens, B. E., Sallis, J. F., \& Frank, L. D. (2003). Environmental correlates of walking and cycling: findings from the transportation, urban design, and planning literatures. Annals of Behavioral Medicine, 25(2), 80-91. http://dx.doi.org/10.1207/S15324796ABM2502_03. PMid:12704009.

Sallis, J. F. (2009). Measuring physical activity environments: a brief history. American Journal of Preventive Medicine, 36(4, Supl), S86-S92. http://dx.doi.org/10.1016/j.amepre.2009.01.002. PMid:19285214.

Sallis, J. F., Bauman, A., \& Pratt, M. (1998). Environmental and policy interventions to promote physical activity. American Journal of Preventive Medicine, 15(4), 379-397. http://dx.doi.org/10.1016/S0749-3797(98)00076-2. PMid:9838979.

Shannon, C. E. (1948). A mathematical theory of communication. The Bell System Technical Journal, 27(3), $379-423$. http://dx.doi.org/10.1002/j.1538-7305.1948.tb01338.x.

Shashank, A., \& Schuurman, N. (2019). Unpacking walkability indices and their inherent assumptions. Health \& Place, 55, 145-154. http://dx.doi.org/10.1016/j.healthplace.2018.12.005.

Southworth, M. (2005). Designing the walkable city. Journal of Urban Planning and Development, 131(4), $246-257$. http://dx.doi.org/10.1061/(ASCE)0733-9488(2005)131:4(246).

Vieira, S. (2008). Introdução à bioestatística (4. ed.). Rio de Janeiro: Elsevier.

Wang, H., \& Yang, Y. (2019). Neighbourhood walkability: a review and bibliometric analysis. Cities, 93, 43-61. http://dx.doi.org/10.1016/j.cities.2019.04.015.

Yin, R. K. (2001). Estudo de caso: planejamento e métodos (2. ed.). São Paulo: Bookman Companhia.

Zhang, M., \& Kukadia, N. (2005). Metrics of urban form and the modifiable areal unit problem. Transportation Research Record: Journal of the Transportation Research Board, 1902(1), 71-79.

http://dx.doi.org/10.1177/0361198105190200109.

Editor: Fábio Duarte

Recebido: Mar. 17, 2019

Aprovado: Maio 09, 2020 